\title{
Epidemiology and Clinical Characteristics of Individuals with Hepatitis C Virus Infection in the United States, 2017-2019
}

\author{
Nancy Reau • Mark S. Sulkowski · Emmanuel Thomas • Vinay Sundaram • Qingqing Xu • Wei-Han Cheng • \\ Steven E. Marx - Oscar A. Hayes · Shivaji R. Manthena · Viktor Chirikov - Douglas E. Dylla · Hannah Brooks • \\ Jana M. Carabino $\cdot$ Sammy Saab
}

Received: July 29, 2021 / Accepted: September 17, 2021 / Published online: October 27, 2021

(c) The Author(s) 2021

\section{ABSTRACT}

Introduction: Hepatitis C virus (HCV) is the most common bloodborne chronic infection in the US. Following approval of highly effective, direct-acting antivirals in 2014, the diagnostic

Supplementary Information The online version contains supplementary material available at https:// doi.org/10.1007/s12325-021-01928-y.

N. Reau

Rush University Medical Center, Chicago, IL, USA

M. S. Sulkowski

Johns Hopkins University School of Medicine,

Baltimore, MD, USA

E. Thomas

University of Miami Miller School of Medicine,

Miami, FL, USA

V. Sundaram

Department of Medicine and Comprehensive

Transplant Center, Cedars-Sinai Medical Center,

Los Angeles, CA, USA

Q. Xu · W.-H. Cheng · S. E. Marx · O. A. Hayes .

S. R. Manthena - D. E. Dylla · H. Brooks .

J. M. Carabino

AbbVie Inc., North Chicago, IL, USA

V. Chirikov

OPEN Health, Bethesda, MD, USA

S. Saab $(\bowtie)$

UCLA Medical Center, 200 Medical Plaza Driveway, Los Angeles, CA 90095, USA

e-mail: SSaab@mednet.ucla.edu and treatment rates for HCV infection in the US have evolved. This study assessed the number of individuals with HCV screening or diagnostic testing and the clinical characteristics and treatment of HCV-infected individuals between 2017 and 2019.

Methods: Individuals screened for HCV antibody and/or tested for HCV ribonucleic acid (RNA) from 2017 to 2019 by two large US laboratory companies were included in this analysis. Clinical characteristics, such as HCV genotype, fibrosis stage, HIV coinfection and demographics, were assessed in HCV RNA-positive individuals. HCV treatment and subsequent achievement of sustained virologic response were imputed using data-driven algorithms based on successive viral load decline and negativity.

Results: From 2017 to 2019, the number of individuals tested for HCV antibody increased by $5.7 \%$, from $7,580,303$ in 2017 to $8,009,081$ in 2019. The percentage of individuals tested who were HCV antibody positive was stable, ranging from $5.0 \%$ in 2017 to $4.9 \%$ in 2018 and 2019. The number of HCV RNA-positive individuals decreased by $5.0 \%$ from 382,500 in 2017 to 363,532 in 2019. Of HCV RNA-positive individuals, the proportions with genotype (GT) 3 and minimal fibrosis increased over time; proportions of individuals aged $<40$ years increased, while the proportion aged 50 to 59 years decreased. Treatment rates increased from $23.4 \%$ in 2017 to $26.8 \%$ in 2019 . 
Conclusions: The percentage of HCV antibodypositive individuals remained stable from 2017 to 2019. The number of individuals tested HCV RNA positive decreased over the years. Demographics shifted toward a younger population with less fibrosis and higher rates of GT3. More than $70 \%$ of diagnosed individuals were not treated during this interval, highlighting a need for unfettered access to treatment.

Keywords: Epidemiology; Hepatitis C virus; Screening; Treatment

\section{Key Summary Points}

Why carry out this study?

This study describes the hepatitis $C$ virus (HCV) care cascade from HCV antibody screening and HCV ribonucleic acid (RNA) diagnostic testing to treatment and cure in the US in 2019, based on the largest and most current dataset of non-extrapolated data using a robust study design and advanced analytical techniques

This dataset answers the important question of "what proportion of individuals received a positive HCV RNA test from 2017 to 2019?" and describes the characteristics of individuals with HCV in the US in terms of age, genotype, fibrosis stage and geographic region

\section{What was learned from the study?}

The number of individuals HCV screened and treated increased from 2017 to 2019; however, most infected individuals remain untreated

Understanding the number of individuals screened, diagnosed and treated over time and identifying gaps in care may help to orient intervention efforts and highlight the need for unfettered access to treatment for all individuals

\section{INTRODUCTION}

Hepatitis C viral (HCV) infection is one of the most common bloodborne chronic infections in the US. The treatment landscape of HCV has fundamentally improved since development and approval of direct-acting antivirals (DAAs) for treatment of chronic $\mathrm{HCV}$, which offer simpler treatment that is highly effective with shorter durations [1, 2]. Using data collected early in the DAA era (2013-2016), the National Health and Nutrition Examination Survey (NHANES) estimated the overall US prevalence at 2.3 million people infected with $\mathrm{HCV}$ [3]. Prior analysis by our group has shown that the number of persons screened for HCV antibody increased from 2013 to 2016, with a corresponding increase in confirmatory ribonucleic acid (RNA) testing $[4,5]$. Since that period, the percentage of the population that is screened, diagnosed or treated for $\mathrm{HCV}$ infection has likely evolved rapidly owing to changes in screening guidance, treatment options and access to therapy and the incidence of HCV in at-risk populations, namely persons who use drugs (PWUD) [6]. Rates of acute infection have risen 63\% between 2015 and 2019 in the US, with $63 \%$ of cases in 2019 occurring in persons aged 20-39 years, consistent with age groups most impacted by the opioid crisis [7]. The rate of newly reported chronic infections in 2019 was 56.7 per 100,000 individuals and follows a biphasic pattern, with cases of new infections highest among those aged 20-39 years and $55-70$ years $[7,8]$, further amplifying the need for accurate, up-to-date HCV epidemiology information. In the US, $67 \%$ of incident cases of $\mathrm{HCV}$ infection are believed to be due to injection drug use [7]. Furthermore, despite the availability of curative treatment and universal screening recommendations $[6,9,10]$, many individuals (> 39\%) with HCV are unaware of their disease, and in those who have been screened, the HCV care cascade shows few receive treatment $[8,11]$.

Given these developments, a better understanding of the changing landscape of $\mathrm{HCV}$ screening and treatment, as well as the clinical characteristics of diagnosed individuals, may 
facilitate targeting of resources to increase HCV screening and treatment. Improved understanding of the care cascade of HCV individuals in the US may support the World Health Organization (WHO)'s goal of HCV elimination as a major burden by 2030 . The NHANES estimates extrapolated prevalence of HCV from 15 US counties, Centers for Disease Control and Prevention (CDC) provides yearly estimates of incident infection through 2019, and state Department of Health data provide information on HCV prevalence from 2000 to 2018. However, there is a lack of real-world data sources reporting on the observed diagnostic, prevalence and treatment rates of HCV infection and clinical characteristics of individuals with $\mathrm{HCV}$ infection. This study utilizes data from large laboratory companies combining patient information and clinical characteristics stratified by year to fill key evidence gaps and provide the most recent data regarding the screening/testing, clinical characteristics and treatment of individuals with HCV in the US from 2017 to 2019.

\section{METHODS}

\section{Data Source and Patient Population}

This study used a secondary, de-identified dataset combined from two large laboratory companies in the US. This derived dataset represents the largest available HCV laboratory dataset in the US. Records of all individuals who were screened for HCV antibody and/or tested for HCV RNA from 2017 to 2019 were retrieved and included in this analysis. Not all included individuals had both HCV antibody and HCV RNA tests.

Patient characteristics, including age (in years), sex (female, male, or unknown) and region of residence (East, South, Midwest or West) were available for all individuals included in the analysis. An individual's region of residence was determined by the location of $\mathrm{HCV}$ RNA testing and diagnosis (Supplementary Material Table S1). For individuals who tested positive for HCV RNA, additional information was retrieved from both laboratory datasets for the following variables: HCV genotype; laboratory results that facilitate calculation of fibrosis stage, including liver alanine aminotransferase, aspartate aminotransferase and platelets; and human immunodeficiency virus (HIV) diagnosis.

\section{Fibrosis Stage Calculation}

Fibrosis stage was calculated among HCV RNApositive individuals using the levels of liver alanine aminotransferase, aspartate aminotransferase and platelets as the modified fibrosis 4 (FIB-4) index and categorized as $F 0(<0.97)$, $F 1$ (0.97-1.44), F2 (1.45-3.25), F3 (3.26-5.20) or $F 4(>5.20)[12,13]$. Individuals with $F 4$ fibrosis stage were classified as cirrhotic [12].

\section{Algorithms for Treatment Receipt and Achievement of Sustained Virologic Response}

\section{Treatment Receipt}

Owing to the lack of information on treatment and continuity of medical or pharmacy benefit enrollment in the source data, receipt of $\mathrm{HCV}$ treatment was determined based on a viral load decline of at least $1.2 \times \log 10$ units since the first positive HCV RNA test, indicating that treatment was initiated in the immediate period prior to the decline $[12,14]$. The year of treatment was assigned for the year in which such decline since a positive HCV RNA viral load was detected. Direct information on treatment timing, type or duration was not available in the data source.

\section{Prediction of Individuals Attaining Sustained Virologic Response}

Data-driven machine learning algorithms were employed to identify individuals who achieved sustained virologic response (SVR) or virologic cure based on successive decline in HCV RNA viral loads. Detailed methodology for development of the algorithm was previously described [12]. Briefly, machine learning predictive models were built and validated using a separate set of 92,099 treated HCV individuals with medical and pharmacy claims available in the Symphony Health Solutions (SHS) medical and 
pharmacy claims dataset from 2017 to 2019. Individuals in the current laboratory dataset who were predicted to have achieved SVR from the machine learning algorithms were classified as cured in the year following the year of treatment (e.g., individuals flagged as initiating treatment in 2018 were classified as treated in 2018 and cured in 2019).

\section{Viremic Status}

Because individuals might have varied followup duration and/or inconsistent HCV RNA measurements in the years from 2017 to 2019, a longitudinal method was applied to impute their HCV viremic status over multiple years. Individuals who had two positive HCV RNA values with gap years in between were assumed to stay HCV viremic in the gap years.

\section{Observed Rates of HCV Screening and Diagnostic Testing}

Observed numbers of HCV antibody-screened, HCV antibody-positive and HCV RNA-positive individuals were assessed for each year from 2017 to 2019. The proportion of individuals who were HCV antibody positive among all individuals HCV antibody screened was calculated.

\section{Rates per 100,000 Individuals}

Observed HCV antibody-screened, HCV antibody-positive and HCV RNA-positive rates per 100,000 individuals in each year were calculated by dividing the observed number of individuals by the US Census population estimates from 2017 to 2019, respectively.

\section{Statistical Analysis}

This study was descriptive in nature. After retrieving and combining data from the two laboratory databases, observed numbers of individuals screened for HCV antibody, tested HCV antibody positive and tested HCV RNA positive were reported. The observed number of individuals who were HCV antibody screened, tested HCV antibody positive and tested HCV RNA positive was stratified by age for the year
2019; the observed rate per 100,000 individuals for those three measures was presented similarly for 2019. Cured individuals predicted from the machine learning algorithms were removed from each year's estimates. The total number of individuals who remained HCV RNA positive and not cured was reported for the respective years between 2017 and 2019. The percent change in observed number of individuals HCV antibody tested, HCV antibody positive and HCV RNA positive between each respective year (2017 to 2018, 2018 to 2019) and between 2017 and 2019 was reported. For those individuals who remained HCV RNA positive in each year, demographic and clinical characteristics, including age, gender, region, HCV genotype, fibrosis status, renal status, HIV coinfection and treatment status (treated or untreated), were summarized using descriptive statistics to describe the sample of participants. Means and standard deviations were reported for normally distributed continuous variables, medians and interquartile ranges for non-normally distributed continuous variables and frequencies and percentages (\%) for categorical variables. The predictive performance of the machine learning algorithms was summarized by metrics of sensitivity, specificity and accuracy. Percentages of SVR or cure rate in the SHS and laboratory databases were calculated as well. Mortality was not determined owing to limitations of the database.

\section{Software}

Data cleaning and manipulation were performed using SAS 9.4 (Cary, NC, USA). Machine learning algorithms were developed in $\mathrm{R}$ software (R Foundation for Statistical Computing, Vienna, Austria).

\section{Compliance with Ethics Guidelines}

With permission, this study utilized de-identified retrospective data from two US laboratory datasets. Because the data were de-identified, no ethics committee approval was required. Additionally, as this study is based on laboratory data, it does not contain any new studies with human or animal subjects performed by any of the authors. 


\section{RESULTS}

\section{Age Distribution of Screening and Diagnostic Testing in 2019}

Observed numbers of individuals in 2019 who were HCV antibody screened, HCV antibody positive and HCV RNA positive were stratified by age, and the percentage of individuals within each age category is presented in Fig. 1. In 2019, the observed number of individuals screened for HCV antibody followed a bimodal age distribution, with the percentage of individuals
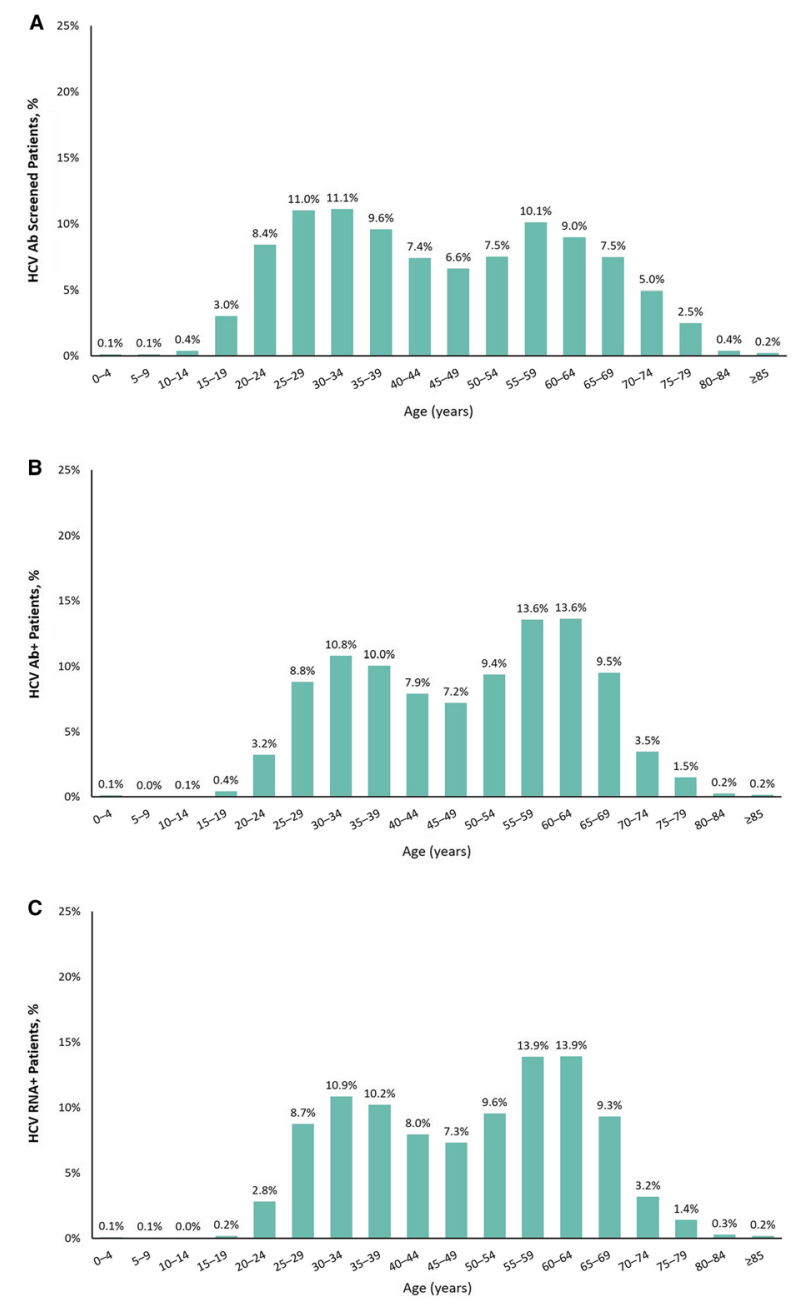

Fig. 1 Age distribution of the number of individuals as well as the observed rates per 100,000 individuals screened for $\mathrm{HCV} \mathrm{Ab}(\mathbf{A})$, positive for $\mathrm{HCV} \mathrm{Ab}(\mathbf{B})$ and positive screened highest among individuals aged 25-34 and 55-59 years (Fig. 1A). The rate of screening per 100,000 individuals followed a similar age distribution, with observed rates highest among individuals aged 25-34 years and 55-59 years. The age distribution was similar between individuals who were $\mathrm{HCV}$ antibody positive and those who were HCV RNA positive. Among individuals who were HCV RNA positive, 21\% were aged 30 to 39 years and $28 \%$ were aged 55 to 64 years (Fig. 1B, C). The rate of HCV RNA positivity per 100,000 individuals followed a similar age distribution as the age-stratified
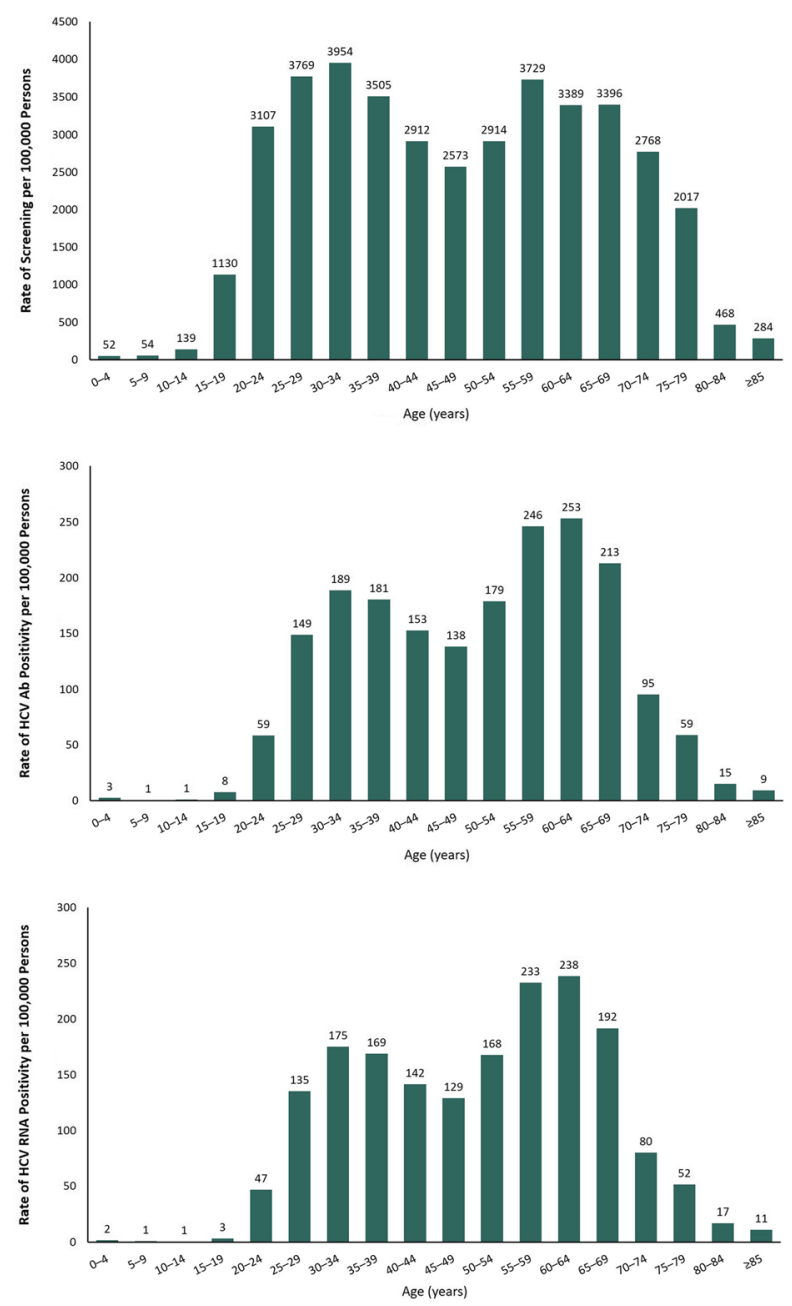

for HCV RNA (C) in 2019. $A b$ antibody, $H C V$ hepatitis $\mathrm{C}$ virus, $R N A$ ribonucleic acid 
proportions of individuals who were HCV RNA positive, with highest rates among those aged 55 to 64 years and 30 to 39 years (Fig. 1C).

\section{Changes in Screening and Diagnostic Testing from 2017 to 2019}

From 2017 to 2019, the observed number of individuals tested for HCV antibody increased from 7,580,303 in 2017 to 7,906,178 in 2018 and 8,009,081 in 2019 (Table 1). Of these, the percentage of individuals who tested $\mathrm{HCV}$ antibody positive remained relatively stable, from $5.0 \%(382,451)$ in $2017,4.9 \%(386,016)$ in
2018 , to $4.9 \%(394,666)$ in 2019 (Table 1$)$. The number of individuals who were HCV RNA positive increased from 2017 to 2018 and decreased from 2017 to 2019.

\section{Observed Screening and Diagnostic Rates per 100,000 Individuals from 2017 to 2019}

The rate per 100,000 individuals screened for HCV antibody increased from 2308 in 2017 to 2423 in 2018 and remained stable from 2018 to 2019 (rate: $2417 / 100,000$ ) (Table 1). The rate of HCV antibody-positive individuals per 100,000 individuals remained stable, from 117 in 2017 to 118 in 2018 and 119 in 2019. Among

Table 1 Observed number and rates per 100,000 persons of individuals screened, diagnosed and treated for HCV from 2017 to 2019

\begin{tabular}{|c|c|c|c|c|}
\hline & 2017 & 2018 & 2019 & $\begin{array}{l}\text { \% Change } \\
2017-2019\end{array}$ \\
\hline HCV Ab screened, $\mathrm{N}$ & $7,580,303$ & $7,906,178$ & $8,009,081$ & - \\
\hline Change from previous year, $\%$ & - & 4.3 & 1.3 & 5.7 \\
\hline $\mathrm{HCV} \mathrm{Ab}$ screening rate $^{\mathrm{a}}$ & 2308 & 2423 & 2417 & - \\
\hline Change from previous year, $\%$ & - & 5.0 & -0.3 & 4.7 \\
\hline $\mathrm{HCV}$ Ab positive, $\mathrm{N}$ (\% positive of screened) & $382,451(5.0)$ & $386,016(4.9)$ & $394,666(4.9)$ & - \\
\hline Change from previous year, $\%$ & - & 0.9 & 2.2 & 3.2 \\
\hline $\mathrm{HCV}$ Ab positive rate ${ }^{\mathrm{a}}$ & 117 & 118 & 119 & - \\
\hline Change from previous year, $\%$ & - & 0.9 & 0.9 & 1.7 \\
\hline HCV RNA positive, $\mathrm{N}$ & 382,500 & 395,524 & 363,532 & - \\
\hline Change from previous year, $\%$ & - & 3.4 & -8.1 & -5.0 \\
\hline HCV RNA positivity rate ${ }^{a}$ & 116 & 121 & 110 & - \\
\hline Change from previous year, $\%$ & - & 4.3 & -9.1 & -5.2 \\
\hline Treated, N & 89,490 & 94,116 & 97,588 & - \\
\hline Change from previous year, $\%$ & - & 5.2 & 3.7 & 9.1 \\
\hline Percent treated, ${ }^{\mathrm{b}} \%$ & 23.4 & 23.8 & 26.8 & - \\
\hline Change from previous year, $\%$ & - & 1.7 & 12.6 & 14.5 \\
\hline
\end{tabular}

$A b$ antibody, $H C V$ hepatitis $\mathrm{C}$ virus, $R N A$ ribonucleic acid

${ }^{a}$ Rate per 100,000 persons

${ }^{\mathrm{b}}$ Among HCV RNA-positive individuals 
individuals with a positive $\mathrm{HCV}$ antibody test and a follow-up HCV RNA test in 2019, 42.4\% tested positive for HCV RNA, resulting in an observed rate of 110 per 100,000 individuals, a decrease from 116 in 2017 and 121 in 2018 (Table 1).

\section{Clinical Characteristics of Individuals Who Were HCV RNA Positive from 2017 to 2019}

The total as-observed number of individuals with active HCV infection (HCV RNA positive) was 363,532 in 2019, which represents a slight decrease $(-5.0 \%)$ from the 382,500 HCV RNApositive individuals in 2017. Individuals may have appeared in more than 1 year of observation if there was no successive decline in HCV RNA viral loads. Between 2017 and 2019, the number and proportion of individuals who were HCV RNA positive and aged $<40$ years numerically increased from $97,462(25.5 \%)$ in 2017 to 119,797 (33.0\%) in 2019, while the proportion aged 50 to 69 years old decreased (Table 2). Proportions were relatively consistent for other age groups over the same time frame. Sex ratio was relatively consistent during this time frame, with males representing $>60 \%$ of all HCV RNA-positive individuals.

Of people who tested HCV RNA positive from 2017 to 2019, 78.9\%, 76.6\% and $77.6 \%$ had data available for HCV genotype in 2017, 2018 and 2019, respectively (Table 2). The percentage of individuals diagnosed with genotype $3 \mathrm{HCV}$ increased over time $(12.9 \%$ in 2017 , $14.3 \%$ in 2018 and $15.0 \%$ in 2019). The percentage of individuals diagnosed with fibrosis stage $F 0$ and $F 1$ (no scarring/fibrosis or minimal scarring/fibrosis) increased over time $(49.4 \%$ in $2017,52.5 \%$ in 2018 and $55.8 \%$ in 2019). Correspondingly, the percentage of individuals with fibrosis stage $F 3$ and $F 4$ decreased over time $(27.2 \%$ in $2017,25.1 \%$ in 2018 and $22.8 \%$ in 2019) (Table 2).

The proportion of all observed individuals in the US who were HCV RNA positive decreased in the East (18.6\% in 2017, 18.5\% in 2018 and $16.7 \%$ in 2019) and increased in the South (44.0\% in $2017,44.6 \%$ in 2018 and $45.5 \%$ in 2019) and West $(26.7 \%$ in $2017,28.1 \%$ in 2018 and $28.3 \%$ in 2019) (Table 2).

\section{Percentage of Individuals Treated from 2017 to 2019}

According to our definition of treatment, which was based on sequential RNA viral load measurements, $26.8 \%$ of individuals who were HCV RNA positive were treated in 2019 . This represents an increase from $23.4 \%$ and $23.8 \%$ for those who were treated in 2017 and 2018, respectively (Table 1).

\section{Prediction of SVR/Cure}

The predictive performance of machine learning algorithms in terms of accuracy, sensitivity and specificity is summarized in Supplementary material Table S2, along with the prediction of percentage of cured individuals who were predicted to have attained SVR. The predicted SVR rates stayed stable and $>95 \%$ across the three datasets from 2017 to 2019, demonstrating a high cure rate (Supplementary material Table S2). Of note, predicted cure rates were similar to the observed cure rates in the SHS dataset.

\section{DISCUSSION}

In this study, we examined screening, diagnosis, clinical characteristics and treatment of individuals with $\mathrm{HCV}$ infection in the US between 2017 and 2019. To the best of our knowledge, this is the largest study to describe the HCV care continuum based on actual confirmed antibody and HCV RNA positivity from non-extrapolated data in 2019, prior to the outbreak of severe acute respiratory syndrome coronavirus 2 (SARS-CoV-2). Understanding screening, diagnostic and treatment rates over time and identifying gaps in care may help to orient intervention efforts and highlight the need for unrestricted access to treatment for all individuals.

This study identified 8,009,081 individuals screened for HCV antibodies, compared to the approximately 5 million previously identified from 2013 to 2016 using a similar methodology [12]. The number of individuals screened for 
Table 2 Characteristics of individuals who tested HCV RNA positive from 2017 to 2019

\begin{tabular}{|c|c|c|c|c|}
\hline Variable & Statistic or category & $\begin{array}{l}2017 \\
N=382,500\end{array}$ & $\begin{array}{l}2018 \\
N=395,524\end{array}$ & $\begin{array}{l}2019 \\
N=363,532\end{array}$ \\
\hline Treatment status, $n(\%)$ & Untreated & $293,010(76.6)$ & $301,408(76.2)$ & $265,944(73.2)$ \\
\hline Median age & Years (IQR) & $54(39-61)$ & $53(37-61)$ & $51(36-61)$ \\
\hline \multirow[t]{6}{*}{ Age, $n(\%)^{\mathrm{a}}$} & $<40$ years & $97,462(25.5)$ & $117,084(29.6)$ & $119,797(33.0)$ \\
\hline & $40-49$ years & $51,684(13.5)$ & $56,297(14.2)$ & $55,512(15.3)$ \\
\hline & $50-59$ years & $113,702(29.7)$ & $104,195(26.4)$ & $85,211(23.5)$ \\
\hline & $60-69$ years & $100,604(26.3)$ & $97,946(24.8)$ & $84,336(23.2)$ \\
\hline & $\geq 70$ years & $19,359(5.1)$ & $19,754(5.0)$ & $18,374(5.1)$ \\
\hline & Missing & $332(<0.1)$ & $248(<0.1)$ & $302(<0.1)$ \\
\hline \multirow[t]{3}{*}{ Sex, $n(\%)$} & Female & $143,904(37.6)$ & $147,740(37.4)$ & $131,680(36.3)$ \\
\hline & Male & $238,152(62.3)$ & $246,954(62.5)$ & $231,010(63.7)$ \\
\hline & Unknown & $444(0.12)$ & $180(0.05)$ & $193(0.05)$ \\
\hline \multirow[t]{4}{*}{ Region, $n$ (\%) } & East & $71,307(18.6)$ & $73,008(18.5)$ & $60,856(16.7)$ \\
\hline & Midwest & $40,754(10.7)$ & $35,053(8.9)$ & $34,369(9.5)$ \\
\hline & South & $168,193(44.0)$ & $176,520(44.6)$ & $165,497(45.5)$ \\
\hline & West & $102,246(26.7)$ & $110,943(28.1)$ & $102,810(28.3)$ \\
\hline \multirow[t]{6}{*}{ Genotype, $n(\%)^{\mathrm{a}}$} & Genotype 1 & $224,146(74.3)$ & $220,460(72.7)$ & $203,310(72.1)$ \\
\hline & Genotype 2 & $34,044(11.3)$ & $34,641(11.4)$ & $31,845(11.3)$ \\
\hline & Genotype 3 & $38,902(12.9)$ & $43,357(14.3)$ & $42,407(15.0)$ \\
\hline & Genotype 4 & $3103(1.0)$ & $3379(1.1)$ & $3346(1.2)$ \\
\hline & Genotype 5/6 & $1503(0.5)$ & $1281(0.4)$ & $1035(0.4)$ \\
\hline & Missing & $80,802(21.1)$ & $92,406(23.4)$ & $81,589(22.4)$ \\
\hline \multirow[t]{5}{*}{ Fibrosis stage, $n(\%)^{\mathrm{a}}$} & $F 0-1$ & $168,920(49.4)$ & $183,412(52.5)$ & $179,261(55.8)$ \\
\hline & $F 2$ & $80,296(23.5)$ & $78,426(22.4)$ & $68,917(21.4)$ \\
\hline & $F 3$ & $31,612(9.3)$ & $30,472(8.7)$ & $25,792(8.0)$ \\
\hline & $F 4$ & $61,016(17.9)$ & $57,193(16.4)$ & $47,466(14.8)$ \\
\hline & Missing & $40,656(10.6)$ & $46,021(11.6)$ & $42,096(11.6)$ \\
\hline HIV infection, $n(\%)$ & Yes & $8988(2.4)$ & $8026(2.0)$ & $6730(1.9)$ \\
\hline
\end{tabular}

$H C V$ hepatitis $\mathrm{C}$ virus, $H I V$ human immunodeficiency virus, $I Q R$ interquartile range, $R N A$ ribonucleic acid ${ }^{a}$ Percentages based on non-missing values 
HCV antibody increased from 2017 to 2019, while the number of individuals who tested HCV RNA positive increased from 2017 to 2018 but decreased overall from 2017 to 2019 . This is in contrast to a previous analysis that found increases in the number of individuals screened for HCV antibody from 2013 to 2016 and a corresponding increase in confirmatory RNA testing, which may reflect the introduction of reflex RNA testing [5]. Increases in screening rates over time may be due to increases in injection drug use, improved surveillance [15] and universal screening recommendations [10]. The observed proportion of individuals who were $\mathrm{HCV}$ antibody positive observed in our study remained relatively stable between 2017 and 2019, suggesting a continued need for universal screening efforts as an essential tool in identifying HCV-infected individuals.

To understand changing characteristics of screened and diagnosed individuals, our study stratified the observed number of individuals $\mathrm{HCV}$ antibody screened, tested HCV antibody positive and tested HCV RNA positive by age for 2019. A bimodal age distribution was observed for all three measures of screening and diagnostic testing. Notably, in 2019, individuals aged 25-34 years made up the highest proportion of individuals who were HCV antibody screened. One potential explanation for this is that an estimated $67 \%$ of new infections are the result of illicit drug use, primarily among younger generations $[7,15]$. These results reinforce the need for one-time, opt-out universal $\mathrm{HCV}$ testing and treatment and repeat testing among high-risk individuals, especially PWUD.

The bimodal age distribution of individuals who are HCV RNA positive in our dataset is consistent with CDC 2019 HCV surveillance data of newly diagnosed individuals with HCV [7]. In our analysis, observed rates of HCV RNA positivity were highest in individuals aged 55-64 years and second highest in individuals aged 30-39 years. In both datasets, individuals aged 30-39 years were disproportionally impacted by HCV, consistent with the age groups most impacted by the nation's opioid crisis [7]. Previous analyses by our group from 2013 to 2016 also saw increases in HCV screening and diagnosis among younger individuals, supporting the observations of the more current 2019 dataset [12]. These results also support earlier analysis of NHANES data through 2016, which found that, although HCV rates were increasing in young people, most prevalent infections occurred in people born between 1945 and 1969 [16]. One explanation for the continued high proportion of older individuals in our study is that the individuals included in this analysis are engaged in HCV care, as they have recent HCV tests, while not accounting for individuals disengaged in care, including PWUD and younger persons. Furthermore, a recent study highlighted that $17 \%$ of adults have never heard of HCV and that younger adults specifically were more likely than older adults to have no awareness of HCV [17].

We also observed an increase in the proportion of HCV genotype 3 infection among individuals who are HCV RNA positive over time in our study. This finding correlates with the increase of HCV genotype 3 infection among younger adults and injection drug users [18-20]. An additional observation was the reduction in the proportion of HCV RNA-positive individuals with cirrhosis over time. This finding is likely to be explained by the prioritization of treatment of patients with cirrhosis and restrictions on treatment access based on fibrosis stage as well as potentially increased motivation to seek treatment by patients with cirrhosis.

Although we observed moderately increased treatment rates over time, most HCV RNA-positive individuals are still not being treated, indicating a need for improved efforts to support access to treatment. Previous analysis has also demonstrated that the proportion of individuals treated remains low, even if individuals were referred to a specialist after an HCV diagnosis [4]. Removing barriers to treatment is critical in efforts to contain and to achieve the WHO's announced a goal of eliminating HCV by 2030 through increased prevention, diagnosis and treatment [21]. Despite elimination efforts, there was a growing burden of chronic liver disease between 2007 and 2017, with HCV being a primary driver of disability-adjusted life years caused by chronic liver disease in 2017 
[22], highlighting the need for unfettered access to treatment.

Barriers to treatment may include stigmatization of marginalized patients, particularly PWUD, insurance denial of treatment and restrictive state Medicaid policies. In a previous analysis of 2016 to 2017 pharmacy data from 45 states, treatment was denied for individuals with Medicaid (34.5\%) and private insurance $(52.4 \%)$ at high levels [23]. Sobriety, prescriber and fibrosis stage restrictions, as well as policies that restrict harm reduction services, can limit efforts to achieve HCV elimination [24, 25]. As reported by the National Viral Hepatitis Roundtable and the Center for Health Law and Policy Innovation of Harvard Law School, the number of states with sobriety restrictions decreased between 2017 and 2021 [24, 25]; however, 13 states still require a period of abstinence and 15 states require drug or alcohol screening or counseling [26]. Furthermore, 12 states do not have laws authorizing syringe service program operations and 13 states criminalize hepatitis transmission [24]. Between 2017 and 2021, most states have eased restrictions based on fibrosis status (4 states have restrictions) and prescriber restrictions (18 states have restrictions), which may correlate with the moderate increases in treatment observed [26-29]. In our current study, states in the South and West had the highest proportions of individuals who were HCV RNA positive. Of the 30 states in those 2 regions, 2 have restrictions by fibrosis status, 19 have sobriety restrictions, and 9 have provider restrictions. Of note, regional data included all payer types and are not Medicaid specific, which may cloud restrictive policies that preferentially impact the Medicaid population. Updates on state-level data from 2015 through 2017 are available at the MappingHepC.com website, which reflects the most current trends in HCV epidemiology [30]. To overcome barriers to treatment, subscription or "Netflix" model programs for HCV treatments from pharmaceutical companies in Louisiana and Washington may lead to treatment increases in these states because these subscription models allow the states to treat patients at a reduced cost [31]. Future research and trends will reveal whether these policy changes and subscription models will correlate with improvements in treatment rates. Simplified treatment algorithms and treatment of individuals who are HCV positive by nonspecialists may also aid in improving treatment rates [6].

The effects of the coronavirus disease 2019 (COVID-19) pandemic may create additional barriers to treatment access and achievement of elimination targets. Impacts of COVID-19 on HCV elimination include reallocation of healthcare resources and disruptions in care and access to treatment as well as patient reluctancy to access healthcare services out of fear of contracting COVID-19 [32]. This is significant, as a 1 -year delay in diagnosis and treatment efforts could result in an additional 72,300 liver-related deaths from HCV globally [32]. Furthermore, during the pandemic there may have been an increase in HCV transmission, as suggested by the increase in overdose and overdose-related deaths in the US [33].

Strengths of the study include analysis of the most recent and largest collection of data significantly contributing to efforts supporting $\mathrm{HCV}$ screening, testing and linkage to care in the US. This dataset includes as-observed realworld data of HCV RNA-confirmed cases and their associated clinical characteristics. The study described HCV screening and diagnostic testing among individuals from 52 states and US territories aged 0 to $>85$ years from 2017 to 2019. These data inform on HCV elimination efforts that were occurring before the outbreak of COVID-19 in 2020.

Limitations of this study include the selective nature of our dataset, which was limited to community-dwelling Americans. This circumstance means that no imprisoned individuals were included, which is notable because the prevalence of HCV is high among those engaged in the criminal justice system. Active drug users may be less represented in these commercial laboratories compared to those in the community with prior drug use. Other highrisk patient populations may also be underrepresented in these datasets, including persons receiving hemodialysis. We could also not assess epidemiology in veterans or determine mortality among included individuals due to 
lack of data. Additional limitations are the lack of details pertaining to the specific treatment regimens that were utilized and the use of viral load as a proxy for cured individuals that could be inaccurate owing to insufficient follow-up time. The number of individuals who were HCV RNA positive in our study was obtained from commercial laboratory databases and is likely an underestimate, as individuals tested outside of these laboratories through other HCV screening endeavors were not captured. The data source does not differentiate between acute and chronic infections, although the timing between RNA tests in our data was generally consistent over time with guidelines for RNA tests (i.e., intervals of 4 weeks apart), which was indicative of treatment for chronic disease. Treatment rates by geographical region were not calculated, which limits understanding of the correlation between state Medicaid restrictions and treatment rates. Future studies will aim to extrapolate the overall prevalence of HCV infection in the US, including an estimation of both diagnosed and undiagnosed individuals.

\section{CONCLUSION}

These data inform on the observed number of individuals screened and diagnosed for $\mathrm{HCV}$ infection using the largest available laboratory dataset in the US. Notably, we found that numbers of younger individuals and of those with milder disease are increasing. Data from this study can inform medical and government stakeholders about HCV burden and help define current unmet needs. Future studies are needed to examine estimated prevalence and progress toward elimination after the COVID-19 epidemic.

\section{ACKNOWLEDGEMENTS}

Funding. Financial support for this study and the journal's Rapid Service and Open Access Fees was provided by AbbVie. AbbVie participated in the interpretation of data, review and approval of the publication. All authors contributed to the development of the publication and maintained control over the final content. No honoraria or payments were made for authorship.

Medical Writing, Editorial and Other Assistance. Medical writing assistance was provided by Brian Richardson and Brandy Menges of Fishawack Facilitate, Ltd. (part of Fishawack Health) and funded by AbbVie.

Authorship. All named authors meet the International Committee of Medical Journal Editors (ICMJE) criteria for authorship for this article, take responsibility for the integrity of the work, and have given their approval for this version to be published.

Author Contributions. All authors reviewed and approved the final version of the article. Nancy Reau: study concept and design; interpretation of data; critical revision of the manuscript for important intellectual content. Mark S. Sulkowski: study concept and design; interpretation of data; critical revision of the manuscript for important intellectual content. Emmanuel Thomas: study concept and design; interpretation of data; critical revision of the manuscript for important intellectual content. Vinay Sundaram: study concept and design; critical revision of the manuscript for important intellectual content. Qingqing Xu: study concept and design; interpretation of data; drafting of the manuscript; critical revision of the manuscript for important intellectual content; data acquisition; administrative, technical, or material support; study supervision. Wei-Han Cheng: study concept and design; interpretation of data; critical revision of the manuscript for important intellectual content; data acquisition; administrative, technical, or material support; study supervision. Steven E. Marx: study concept and design; interpretation of data; critical revision of the manuscript for important intellectual content; data acquisition; administrative, technical, or material support; study supervision. Oscar A. Hayes: statistical analysis; interpretation of data; critical revision of the manuscript for important 
intellectual content; administrative, technical, or material support. Shivaji R. Manthena: statistical analysis; interpretation of data; critical revision of the manuscript for important intellectual content; administrative, technical, or material support. Viktor Chirikov: study concept and design; interpretation of data; critical revision of the manuscript for important intellectual content. Douglas E. Dylla: study concept and design; interpretation of data; critical revision of the manuscript for important intellectual content. Hannah Brooks: study concept and design; interpretation of data; critical revision of the manuscript for important intellectual content. Jana M. Carabino: study concept and design; interpretation of data; critical revision of the manuscript for important intellectual content. Sammy Saab: study concept and design; interpretation of data; critical revision of the manuscript for important intellectual content.

Disclosures. Nancy Reau is a consultant for AbbVie, Gilead Sciences, Merck and Co., and Abbott. Her institution has received research support from Abbott, AbbVie, and Gilead Sciences. Mark S. Sulkowski is a consultant for AbbVie and Gilead. His institution has received research support from AbbVie and Gilead Sciences. Emmanuel Thomas: AbbVie: Scientific Advisory Boards, Gilead Sciences: Scientific Advisory Boards and Grant support. Vinay Sundaram is on the speakers' bureau for AbbVie, Salix Pharmaceuticals, Gilead Sciences, and Intercept Pharmaceuticals. Qingqing $\mathrm{Xu}$, WeiHan Cheng, Steven E. Marx, Oscar A. Hayes, Shivaji R. Manthena, Douglas E. Dylla, Hannah Brooks, and Jana M. Carabino are employees of AbbVie and may own AbbVie stock. Viktor Chirikov is an employee of OPEN Health, which received funding to provide technical counsel on the data analysis. Sammy Saab is on the speakers' bureau for Salix Pharmaceuticals.

Compliance with Ethics Guidelines. With permission, this study utilized de-identified data from two US laboratory datasets. Because the data were de-identified, no ethics committee approval was required. Additionally, as this study is based on laboratory data, it does not contain any new studies with human or animal subjects performed by any of the authors.

Data Availability. The datasets generated during and/or analyzed during the current study are available from the corresponding author on reasonable request.

Open Access. This article is licensed under a Creative Commons Attribution-NonCommercial 4.0 International License, which permits any non-commercial use, sharing, adaptation, distribution and reproduction in any medium or format, as long as you give appropriate credit to the original author(s) and the source, provide a link to the Creative Commons licence, and indicate if changes were made. The images or other third party material in this article are included in the article's Creative Commons licence, unless indicated otherwise in a credit line to the material. If material is not included in the article's Creative Commons licence and your intended use is not permitted by statutory regulation or exceeds the permitted use, you will need to obtain permission directly from the copyright holder. To view a copy of this licence, visit http:// creativecommons.org/licenses/by-nc/4.0/.

\section{REFERENCES}

1. Baumert TF, Berg T, Lim JK, Nelson DR. Status of direct-acting antiviral therapy for hepatitis $C$ virus infection and remaining challenges. Gastroenterology. 2019;156:431-45.

2. Yao X, Sangaralingham LR, Ross JS, Shah ND, Talwalkar JA. Adoption of new agents and changes in treatment patterns for hepatitis C: 2010-2014. Am J Manag Care. 2016;22:e224-32.

3. Rosenberg ES, Rosenthal EM, Hall EW, et al. Prevalence of hepatitis $C$ virus infection in US States and the District of Columbia, 2013 to 2016. JAMA Netw Open. 2018;1:e186371.

4. Reau N, Marx S, Manthena S, Strezewski J, Chirikov V. National examination of HCV linkage to care in the United States (2013-2016) based on large realworld dataset. Poster presentation at The Liver Meeting ${ }^{\circledR}$ 2018, November 09-13, 2018, San Francisco, CA, USA 
5. Sulkowski M, Marx S, Manthena S, Strezewski J, Chirikov V. National estimates for HCV screening and diagnosis rates in the United States (2013-2016) based on large real-world dataset. Poster presentation at The Liver Meeting ${ }^{\circledR}$ 2018, November 09-13, 2018, San Francisco, CA, USA

6. American Association for the Study of Liver Diseases and Infectious Diseases Society of America. HCV testing and linkage to care. Page last updated August 27, 2020. https://www.hcvguidelines.org/ evaluate/testing-and-linkage. Accessed January 26, 2021.

7. Centers for Disease Control and Prevention. Viral Hepatitis Surveillance Report - United States, 2019. https://www.cdc.gov/hepatitis/statistics/ 2019surveillance/index.htm. Published May 2021. Accessed June 30, 2021.

8. Ryerson AB, Schillie S, Barker LK, Kupronis BA, Wester C. Vital signs: newly reported acute and chronic hepatitis C cases-United States, 2009-2018. MMWR Morb Mortal Wkly Rep. 2020;69:399-404.

9. Centers for Disease Control and Prevention. Testing recommendations for hepatitis $\mathrm{C}$ virus infection. Page last reviewed July 29, 2020. (https://www.cdc. gov/hepatitis/hcv/guidelinesc.htm\#: :text=CDC\% 20Recommendations\%20for\%20Hepatitis\% 20C,is\%20less\%20than\%200.1\%25*). Accessed January 7, 2021.

10. Force USPST, Owens DK, Davidson KW, et al. Screening for hepatitis $\mathrm{C}$ virus infection in adolescents and adults: US Preventive Services Task Force recommendation statement. JAMA. 2020.

11. Thomas DL. State of the hepatitis C virus care cascade. Clin Liver Dis. 2020;16:8-11.

12. Chirikov VV, Marx SE, Manthena SR, Strezewski JP, Saab S. Development of a comprehensive dataset of hepatitis $C$ patients and examination of disease epidemiology in the United States, 2013-2016. Adv Ther. 2018;35:1087-102.

13. Sterling RK, Lissen E, Clumeck N, et al. Development of a simple noninvasive index to predict significant fibrosis in patients with HIV/HCV coinfection. Hepatology. 2006;43:1317-25.

14. Perelson AS, Guedj J. Modelling hepatitis C therapy-predicting effects of treatment. Nat Rev Gastroenterol Hepatol. 2015;12:437-45.

15. Centers for Disease Control and Prevention. People who use or inject drugs and viral hepatitis. Page last reviewed August 24, 2020.

16. Bradley H, Hall EW, Rosenthal EM, Sullivan PS, Ryerson AB, Rosenberg ES. Hepatitis C Virus
Prevalence in 50 U.S. States and D.C. by Sex, Birth Cohort, and Race: 2013-2016. Hepatol Commun. 2020;4:355-70.

17. Islam JY, Spees L, Camacho-Rivera M, Vidot DC, Yarosh R, Wheldon CW. Disparities in awareness of hepatitis $C$ virus among U.S. adults: an analysis of the 2019 Health Information National Trends Survey. Sex Transm Dis. 2021.

18. Muñoz-Espinosa LE, Trujillo-Trujillo ME, MartínezMacías RF, et al. Increase of drug use and genotype 3 in HCV-infected patients from Central West and Northeast Mexico. Annals Hepatol. 2015;14: 642-51.

19. Ampuero J, Romero-Gómez M, Reddy KR. Review article: HCV genotype 3 - the new treatment challenge. Alimentary Pharmacol Ther. 2014;39: 686-98.

20. Harder J, Walter E, Riecken B, Ihling C, Bauer TM. Hepatitis $C$ virus infection in intravenous drug users. Clin Microbiol Infect. 2004;10:768-70.

21. WHO. Global health sector strategy on viral hepatitis 2016-2021; 2020. https://www.who.int/ hepatitis/strategy2016-2021/ghss-hep/en/. Accessed January 27, 2021.

22. Paik JM, Golabi P, Younossi Y, Saleh N, Nhyira A, Younossi ZM. The growing burden of disability related to chronic liver disease in the United States: Data From the Global Burden of Disease Study 2007-2017. Hepatol Commun. 2021;5:749-59.

23. Gowda C, Lott S, Grigorian M, et al. Absolute insurer denial of direct-acting antiviral therapy for hepatitis C: a national specialty pharmacy cohort study. Open Forum Infect Dis. 2018;5:ofy076.

24. Waters P, Greenwald R, Ninburg M, Simmons State policies limiting progress towards HCV elimination in the U.S.. Poster presentation at The Liver Meeting ${ }^{\circledR}$ 2020, November 13-16, 2020, Virtual.

25. Access HCSoM. Hepatitis C: state of Medicaid access; 2020. stateofhepc.org. Accessed March 17, 20202020.

26. National Viral Hepatitis Roundtable and the Center for Health Law and Policy Innovation of Harvard Law School. Hepatitis C: State of Medicaid Access. Updated May 2021. http://stateofhepc.org/wpcontent/uploads/2021/05/HCV_State-of-MedicaidAccess_May-2021-Progress-Report.pdf. Accessed June 2, 2021.

27. National Viral Hepatitis Roundtable and the Center for Health Law and Policy Innovation of Harvard Law School. Hepatitis C: State of Medicaid Access. Discriminatory State Medicaid Restrictions. 
Updated October 2019. https://stateofhepc.org/ report/. Accessed January 27, 2021.

28. National Viral Hepatitis Roundtable and the Center for Health Law and Policy Innovation of Harvard Law School. Hepatitis c: The State of Medicaid Access-Inforgraphic: See how your state matches up. https://stateofhepc.org/resources/. Accessed January 27, 2021.

29. Greenwald R, Waters P, Cayer S. Enforcement of legal remedies to secure hepatitis $C$ virus treatment with direct-acting antiviral therapies in correctional facilities and Medicaid programs. Public Health Rep. 2020;135:44S-S49.
30. MappingHepC. Interactive map; 2020. https:// mappinghepc.com/maps. Accessed June 22021.

31. Trusheim MR, Cassidy WM, Bach PB. Alternative state-level financing for hepatitis $\mathrm{C}$ treatment-The “Netflix Model." JAMA. 2018;320:1977-8.

32. Blach S, Kondili LA, Aghemo A, et al. Impact of COVID-19 on global HCV elimination efforts. J Hepatol. 2021;74:31-6.

33. Ahmad FB, Rossen LM, Sutton P. Provisional drug overdose death counts. National Center for Health Statistics. 2021. https://www.cdc.gov/nchs/nvss/ vsrr/drug-overdose-data.htm Accessed July 1, 2021. 